American J. of Engineering and Applied Sciences 2 (4): 781-788, 2009

ISSN 1941-7020

(C) 2009 Science Publications

\title{
Robust of Doppler Centroid for Mapping Sea Surface Current by Using Radar Satellite Data
}

\author{
Maged Marghany and Mazlan Hashim \\ Institute of Geospatial Science and Technology, Faculty of Geoinformation Science and Engineering, \\ University Technology Malaysia, 81310 UTM, Skudai, Johore Bahru, Malaysia
}

\begin{abstract}
Problem statement: Sea surface current retrieving from Synthetic Aperture Radar (SAR) is required standard methods due to the complexity of sea surface ocean imaging in SAR data. In this context, various analytical models have been developed which describe overall effects of sea surface roughness on the Doppler signal mechanisms. Nevertheless, such models are limited in the complexity of the sea surface current estimation that can be used. In fact, the resolution of the sea surface Doppler velocity in azimuth direction is typically coarser as compared to the normalized radar cross section image. Approach: This study introduced a new method to retrieve sea surface current from RADARSAT-1 SAR Standard beam mode (S2) data. The method was based on the utilization of the Wavelength Diversity Ambiguity Resolving (WDAR) and Multi Look beat Frequency (MLBF) algorithms to remove Doppler centroid $\left(f_{D C}\right)$ ambiguity. Results: The result showed that the proposed methods are able to correct Doppler centroid $\left(f_{D C}\right)$ ambiguity and produced fine spatial sea surface current variations in S2 mode data. The current velocities were ranged between 0.18 and $0.78 \mathrm{~m} \mathrm{sec}^{-1}$ with standard error of $0.11 \mathrm{~m} \mathrm{sec}^{-1}$. Conclusion: In conclusion, RADARSAT-1 SAR standard beam mode (S2) data can be utilized to retrieve real time sea surface current. Both WDAR and MLBF algorithms are able to provide accurately information on Doppler Centroid $\left(f_{D C}\right)$ in which accurately real time sea surface current can be retrieved from SAR data.
\end{abstract}

Key words: RADARSAT-1 SAR, robust model, sea surface current, wavelength diversity ambiguity resolving, algorithm, multi look beat frequency, algorithm

\section{INTRODUCTION}

Synthetic Aperture Radar (SAR) has been recognized as powerful tool for environmental dynamic studies. Ocean surface current is considered as major element in marine environment. In fact, the climate change, marine pollution and coastal hazardous are basically controlled by intensity of ocean current ${ }^{[1]}$. The main concept to model sea surface current from SAR images is based on Doppler shift ${ }^{[2]}$. In this context, Doppler shift of the radar signal backscattered from the sea surface is occurred by orbital motions of ocean wave and surface currents ${ }^{[4]}$. In fact, the surface velocity relative to the SAR, or equivalently the Doppler shift, relies on the antenna view angle relative to the trajectory ${ }^{[10]}$. Therefore, the Doppler shift, which can be used for determining the line-of-sight velocity of the scatterers and thus the surface currents ${ }^{[1]}$. Furthermore, the distribution of the line-of- sight velocity of the scatterers is associated with the Doppler spectrum within the radar resolution cell ${ }^{[9]}$. A wide range of mathematically and physically based models, however, have been developed to convert a surface Doppler velocity to be of geophysical origin. Although various analytical models have been developed which describe overall effects of sea surface roughness on the Doppler signal mechanisms, such approaches are limited in the complexity of the sea surface current estimation that can be used. In azimuth direction, the resolution of the sea surface Doppler velocity is typically coarser as compared to the normalized radar cross section image ${ }^{[2]}$. In fact Doppler frequency Centroid must be estimated from Doppler spectrum ${ }^{[10]}$. The general geophysical interpretation of surface Doppler velocity, however is imperfect established. For instance, Shemer et al. ${ }^{[12]}$ reported that the surface drift current is significantly different from the surface Doppler velocity. In

Corresponding Author: Maged Marghany, Institute of Geospatial Science and Technology,

Faculty of Geoinformation Science and Engineering, University Technology Malaysia, 81310 UTM, Skudai, Johore Bahru, Malaysia 
contrast, Romeiser et al. ${ }^{[11]}$ stated that a surface Doppler velocity is well correlated with surface currents with strong geostrophic or tidal currents. Because the imaging mechanism of ocean surface current gradients by SAR is complicated due to its nonlinearity. This makes a difficult task to retrieve sea surface current information using a surface Doppler velocity ${ }^{[2]}$. According to Inglanda and Garello ${ }^{[5]}$, the wave-current interaction and velocity bunching effects are the main sources of nonlinearity in the imaging mechanism of ocean surface current by SAR. This impact is known as the tilt bias. Romeiser and Thompson ${ }^{[10]}$, however, have implemented theoretical linear modulation transfer function to express a to solve the problem of tilt bias in order to estimate sea surface Doppler velocity. In this context, Chapron et al. ${ }^{[2]}$ have commanded that the exact shape of the high-frequency spectrum and poor knowledge of linear modulation transfer function are perhaps the main sources in uncertainty for this model. Moreover, they used quantitative forward model which is based on a practical two-scale decomposition of the surface geometry and kinematics where the wind impacts through the wave spectrum is considered. The authors have expressed this contribution as an amplified stokes drift with a gain factor controlled by relative modulation of radar cross section with incident angles. Furthermore, Chapron et al ${ }^{[2]}$ have acquired a surface Doppler velocity by using an average over the random wave phases. In this context, the Doppler Centroid frequency anomaly divided by the electromagnetic wave number assuming that Doppler Centroid frequency anomaly is a simple geometrical mean weighted by normalized radar section of each element ${ }^{[3]}$. Romiser and Thompson ${ }^{[10]}$, nevertheless, stated that when Doppler Centroid estimators are applied to SAR data, biased estimates are often obtained because of anomalies in the received data. Typical anomalies include areas of low SNR, strong discrete targets and radiometric discontinuities.

In this study we address the question of Doppler centroid $\left(f_{D C}\right)$ ambiguity impact on modeling sea surface current movement from RADARSAT-1 SAR standard beam mode (S2). Two hypothesis examined are: (i) Doppler centroid can be acquired accurately by using both Wavelength Diversity Ambiguity Resolving (WDAR) and Multi Look beat Frequency (MLBF) algorithms and (ii) the robust model can be provided accurately estimation of sea surface current from RADARSAT-1 SAR data. In doing so, this study extends the pervious theory of Doppler centroid $\left(f_{D C}\right)$ by implementing robust formula. In addition, it used one single RADARSAT-1 SAR beam mode data i.e., the Standard beam mode (S2).

\section{MATERIALS AND METHODS}

Data set: The SAR data acquired in this study are derived from RADARSAT-1 satellite that involve Standard beam mode (S2) image. RADARSAT-1 SAR data are C-band and have a lower signal-to-noise due to their $\mathrm{HH}$ polarization with a wavelength of $6.6 \mathrm{~cm}$ and frequency of 5.3 GHz. RADARSAT-1 SAR S2 mode data have 3.1 looks and cover an incidence angle of $23.7^{\circ}$ and $31.0^{\circ[2]}$. Further, S2 mode data covers a swath width of $100 \mathrm{~km}$ and ground range resolution of $25 \times 28 \mathrm{~m}$ (Table 1$)$.

In situ measurements: Field measurements are performed between 1 am to $17.00 \mathrm{pm}$ local time at coastal water of Kuala Terengganu and have carried out in March 29 till March 30 2005. Vertical current measurements are obtained from Acoustic Wave and Current (AWAC) equipment (Fig. 1). The deployment location is at $5^{\circ} 31^{\prime} 16^{\prime \prime} \mathrm{N}$ and $103^{\circ} 08^{\prime} 40^{\prime \prime} \mathrm{E}$ in the east coast of Malaysia (Fig. 2) where the location of an artificial reef. The deployment water depth was 18.5 $\mathrm{m}$. Two navigation buoys are used as guidance points to ensure the safety of AWAC equipment (Fig. 1). The procedures are used to calibrate the AWAC are involved: a set up of one burst every half hour that is measured by AWAC, current velocity and direction are measured in bursts of 1024 samples at sampling rate $1 \mathrm{~Hz}$ which are made while the instrument is out of the water (Fig. 1). Information retrieved from AWAC are stored as ASCII format that are involved current velocity and direction data through the water column of $18.5 \mathrm{~m}$. These data are used to validate the results of the sea surface current patterns which are extracted from RADARSAT-1 data.

Table 1: RADARSAT-1 SAR image description

\begin{tabular}{|c|c|c|c|c|c|c|}
\hline Start time & Orbit & Beam & Swath area $(\mathrm{km})$ & Incidence Angle $\left(^{\circ}\right)$ & Width $(\mathrm{km})$ & $\begin{array}{l}\text { Resolution } \\
(\text { Range } \times \text { Azimuth, m) }\end{array}$ \\
\hline $\begin{array}{l}03 / 30 / 2005 \\
6: 57: 16 \mathrm{AM}\end{array}$ & 293D & $\begin{array}{l}\text { Standard-2 } \\
\text { (Descending) }\end{array}$ & 100 & $23.7-31$ & 100 & $25 \times 28$ \\
\hline
\end{tabular}




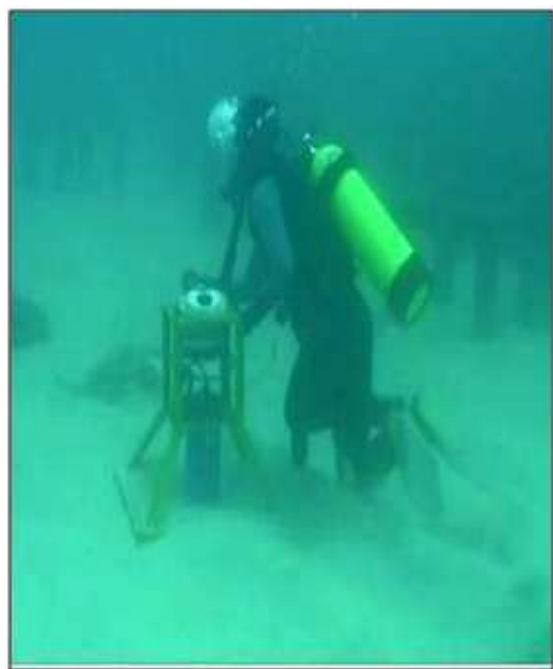

(a)

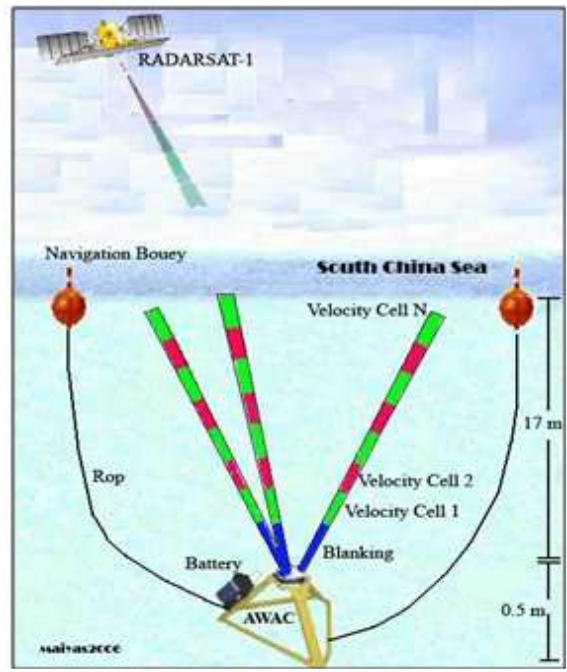

(b)

Fig. 1: AWAC for current measurements (a) real AWAC deployment procedures at sea bottom and (b) sketch of AWAC deployment

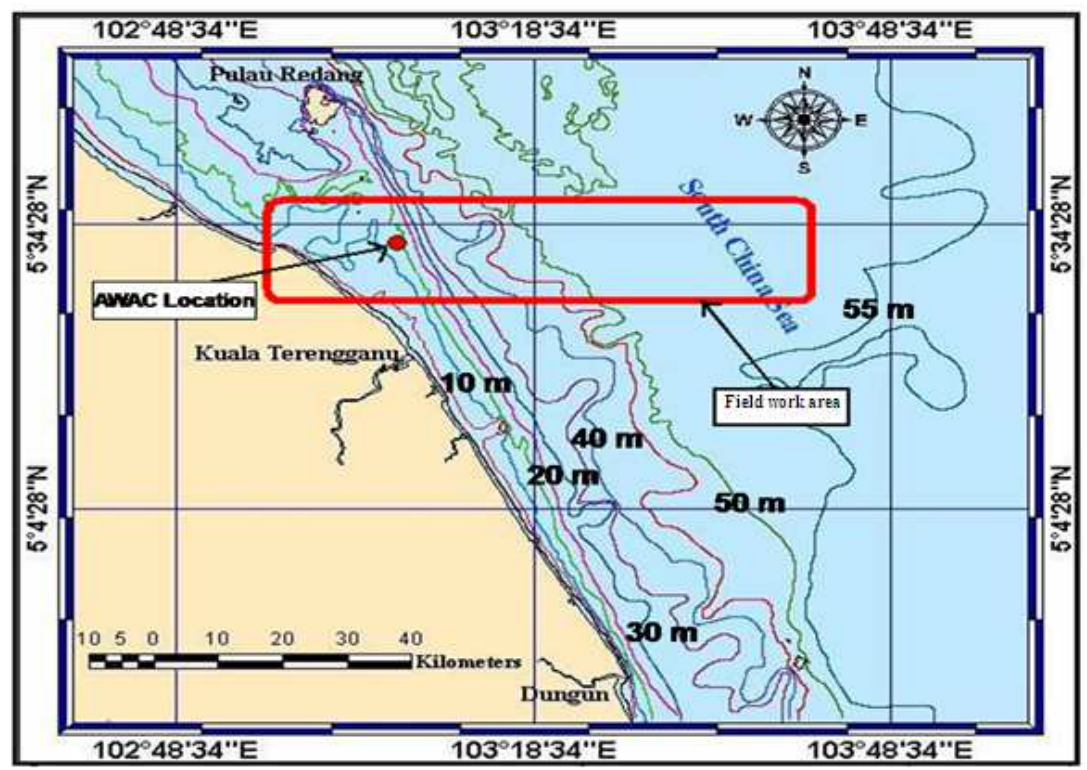

Fig. 2: Location of study area and in situ measurements by AWAC

Doppler centroid model description: In azimuth direction, SAR utilizes the Doppler shift of the complex received field to locate scatterers. This complex field and its associated residual Doppler shift can be used to infer the velocity of these scatterers as advected by ocean currents ${ }^{[4]}$. Further, the spectral density is defined as the response from infinitesimal point scatterers located at $\mathrm{x}_{0}$. Therefore, the Doppler spectral intensity can be given in closed form by assuming non-uniform radar cross section $(\sigma)^{[9]}$ :
$\mathrm{S}(\omega)=\left|\mathrm{E}_{\mathrm{r}}(\omega)\right|^{2}|\mathrm{H}(\omega)|^{2}$

Where:

$\mathrm{E}_{\mathrm{r}}(\omega)=$ A received signal

$H(\omega)=$ System descriptor

The complex received signal in the frequency plane is given by the Fourier transform of the received backscatter $\left(\sigma\left(\mathrm{x}_{0}, \mathrm{t}\right)\right)$ from an infinitesimal point scatterers located at position $\mathrm{x}_{0}{ }^{[9]}$ : 


$$
\mathrm{E}_{\mathrm{r}}\left(\mathrm{x}_{0}, \omega\right)=\int_{-\infty}^{\infty} \sigma\left(\mathrm{x}_{0}, \mathrm{t}\right) \mathrm{e}^{\mathrm{i} \omega \mathrm{t}} \mathrm{dt}
$$

where, $\sigma\left(\mathrm{x}_{0}, \mathrm{t}\right)$ can be given by ${ }^{[9]}$ :

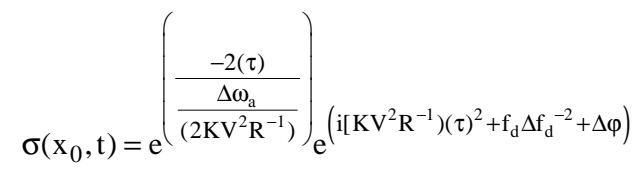

Where:

$$
\begin{aligned}
\mathrm{V} & =\text { The satellite velocity of } 6212 \mathrm{~m} \mathrm{sec}^{-1} \\
\tau & =\text { The delay time } \\
\omega_{\mathrm{a}} & =\text { The received signal azimuthally bandwidth } \\
\mathrm{K} & =\text { Radar wavenumber } \\
\mathrm{R} & =\text { Range } \\
\mathrm{f}_{\mathrm{d}} & =\text { The Doppler frequency } \\
\Delta \mathrm{f}_{\mathrm{d}} & =\text { The gradient change in Doppler frequency }
\end{aligned}
$$

$\mathrm{f}_{\mathrm{d},} \Delta \varphi=$ The phase perturbation due to the long ocean waves with respect to azimuth direction ${ }^{[9]}$

The system descriptor $\mathrm{H}(\omega)$ is obtained through a matched filter which is the complex conjugate of the backscatter based on a point target located midbeam, $\sigma\left(\mathrm{x}_{0}, \mathrm{t}\right)^{[9]}$ is given by:

$$
H(\omega)=e^{\left(\frac{-2 \Delta f_{d}^{-2}}{\Delta \omega_{\mathrm{d}} R\left(2 K V^{2}\right)^{-1}}\right)} e^{\left(-i K V^{2} R^{-1} \Delta f_{d}^{-2}\right)}
$$

The first term in Eq. 2 is a Gussian function and $\Delta \omega_{\mathrm{h}}$ is the processor bandwidth.

The RADARSAT-1 SAR ocean current values have been converted to the horizontal ocean surface current $\mathrm{V}_{\mathrm{c}}$. The radial component of ocean current deduced from RADARSAT-1 SAR data is given in term of the Doppler peak frequency shift, $f_{\max }$, therefore the horizontal ocean current is:

$$
\mathrm{V}_{\mathrm{c}}=\frac{2}{\mathrm{~N}^{\prime}}\left[\frac{\lambda \mathrm{V}\left(1+\Delta \mathrm{f}_{\mathrm{a}} / \Delta \mathrm{f}_{\mathrm{h}}\right)^{2}}{2 \rho_{\mathrm{a}}^{\prime} \sin \theta \sin \Phi}\right]\left(\Delta \mathrm{f}_{\mathrm{a}}\right)^{-1} \cdot \mathrm{f}_{\mathrm{DC}}
$$

where, $\Delta \mathrm{f}_{\mathrm{a}}=\left(\Delta \omega_{\mathrm{a}} / 2 \pi\right), \Delta \mathrm{f}_{\mathrm{h}}=\left(\Delta \omega_{\mathrm{h}} / 2 \pi\right)$ have been used to compute the frequency and $f_{D C}$ is Doppler Centroid frequency. The degraded azimuth resolution $\mathrm{P}_{\mathrm{a}}$ that is caused by orbital acceleration $\left(\mathrm{a}_{\mathrm{r}}\right)$ is given by:

$$
\rho_{\mathrm{a}}^{\prime}=\mathrm{N}^{\prime} \frac{\lambda}{4 \mathrm{Vc}^{-1}}\left[1+\frac{1}{\mathrm{~N}^{\prime 2}}\left(\frac{\pi\left(\mathrm{Rc}^{-1}\right)^{2}}{\lambda} \mathrm{a}_{\mathrm{r}}\right)^{2}\right]^{1 / 2}
$$

where, SAR wavelength, $c$ is speed of light ;and $\mathrm{N}^{\prime}$ is given ${ }^{[9]}$ by:

$$
\mathrm{N}^{\prime}=\left[1+\left(\Delta \omega_{\mathrm{a}}\right)^{2}+\left(\frac{\Delta \omega_{\mathrm{a}}}{\Delta \omega_{\mathrm{h}}}\right)^{2}\right]^{1 / 2}
$$

Equation 7 is considered equivalent to number of multiple looks which leads to degraded resolution over the full bandwidth resolution. The equivalent number of looks; therefore, decreases the bandwidth ${ }^{[9]}$. The main problem is associated with Eq. 1 that is Doppler Centroid $\left(f_{D C}\right)$ estimation. Robust model is one of the standard procedures that is required to estimate $f_{D C}$.

Robust model: The term robust estimation means estimation techniques which are robust with respect to the presence of gross errors in the data. In this context, gross errors are defined as observations which do not fit to the stochastic model of parameter estimation. Further, uncertainties in the estimation of Doppler centroid frequency can lead to completely false results of sea surface current modeling and might even prevent convergence of adjustment. Robust estimators are estimators which are relatively insensitive to limited variations in the frequency distribution function of the Doppler centroid frequency $f_{D C}$. Chapron et al. ${ }^{[2]}$, however, did not take into account the problems of estimating the Doppler Centroid which might be began from a range-compressed dataset acquired by conventional single Pulse Repetition Frequency (PFR) of ENVISAT-ASAR. Therefore, Stefano and Guarnieri ${ }^{[13]}$ stated that for efficiency, the constraint of operating on rangecompressed data is required. Following Stefano and Guarnieri $^{[13]}$, the ambiguous estimation and Wavelength Diversity Ambiguity Resolving algorithm (WDAR) and Multi Look beat Frequency (MLBF) have implemented to correct $f_{D C}$ ambiguity and to fit a fine polynomial estimate in SAR images. First, the RADARSAT-1 SAR image is divided in several blocks. In each blocks both a second order statistic estimator (WDAR) and a higher order technique (MLBF) have been exploited to resolve coarse unambiguous. Doppler centroid. These techniques have been chosen due to the large variation of $f_{D C}$ with range as can be noticed clearly in RADARSAT-1 SAR data. The polynomial inversion model is given by Stefano and Guarnieri ${ }^{[13]}$, is used:

$$
f_{D C}(a, r)=X r^{2}+Y r+Z a+h
$$


Where:

$\begin{aligned} \mathrm{a}, \mathrm{r} \quad & \begin{array}{l}\text { Range and azimuth indexes of the } \\ \text { samples at the center of each block }\end{array} \\ \mathrm{X}, \mathrm{Y}, \mathrm{Z} \text { and } \mathrm{h}= & \text { The polynomial coefficients to be } \\ & \text { estimated }\end{aligned}$

Two steps have been required to achieve the polynomial inversion technique: (i) wrapped plane is regressed and (ii) the model then inverted on the residuals (res). The selection between the both steps is mainly done by means of a threshold on the contrast parameter which is based on the pixel intensity of each block. For instance, unambiguous $\mathrm{f}_{\mathrm{DC}}$ is computed with WDAR in low contrast blocks as compared to MLBF. Taking into account that the value of the ambiguity (p) and the polynomial parameters $(\mathrm{X}, \mathrm{Y}, \mathrm{Z}, \mathrm{h})$, the unambiguous $\mathrm{f}_{\mathrm{DC}}$ polynomial can be given by this formula ${ }^{[13]}$ :

$\widehat{f}_{\text {DC }}(\mathrm{a}, \mathrm{r})=\mathrm{X}_{\text {res }} \mathrm{r}^{2}+\left(\mathrm{Y}_{\mathrm{p}}+\mathrm{Y}_{\text {res }}\right) \mathrm{r}+\left(\mathrm{Z}_{\mathrm{p}}+\mathrm{Z}_{\text {res }}\right) \mathrm{a}+\left(\mathrm{h}_{\mathrm{p}}+\mathrm{h}_{\text {res }}\right)$

Finally, offset frequency is implemented by subtraction of MLBF estimate from WDAR. This is done with an assumption of the ambiguity estimate based on the MLBF technique is correct. Following Rufench et al. ${ }^{[9]}$, the RADARSAT-1 SAR ocean current values must be converted from radial component $\mathrm{V}_{\mathrm{r}}$ to the horizontal ocean component $V_{c}$ by a given equation:

$\mathrm{V}_{\mathrm{c}}=\frac{\mathrm{C} \cdot 0 \cdot 5 \cdot \lambda \cdot \hat{\mathrm{f}}_{\mathrm{DC}}(\mathrm{a}, \mathrm{r})}{\sin \theta \sin \phi}$

Where:

$\theta=$ An incidence angle of RADARSAT-1 SAR data

$\varphi=$ The azimuth angle

$\mathrm{C}=$ Constant value which is determined by using least square method between in situ measured ocean current and the Doppler Centroid $\hat{\mathrm{f}}_{\mathrm{DC}}(\mathrm{a}, \mathrm{r})$ which is a function of surface current velocity

The crucial issue can be raised due to the performing of least square method is a lack of robustness. The least squares error function to be minimized is as follows ${ }^{[3]}$ :

$$
\mathrm{e}^{2}\left(\mathrm{~V}_{\mathrm{c}}\right)=\mathrm{d}^{-1} \sum_{\mathrm{i}} \mathrm{w}^{-1}\left[\mathrm{~V}_{\mathrm{i}}-\mathrm{V}_{\mathrm{c}}\left(\hat{\mathrm{f}}_{\mathrm{DC}}(\mathrm{a}, \mathrm{r})\right]^{2}\right.
$$

Where:

$\mathrm{V}_{\mathrm{i}}=$ Real measured of surface current by using AWAC equipment

$\mathrm{I}=$ Number of observation
$\mathrm{w}=\mathrm{A}$ weight that is assigned to each respective observation

$\mathrm{d}=$ The number of degrees of freedom

The robust standard deviation $\hat{\sigma}$ is estimated by combination of Least Median of Squares (LMedS) method with weighted least squares procedure which can be expressed as:

$$
\hat{\sigma}=1.5\{1+5 / \mathrm{n}-\mathrm{p}\} \operatorname{med} \sqrt{\mathrm{r}_{\mathrm{i}}{ }^{2}}
$$

Where:

$\mathrm{r}_{\mathrm{i}}=$ The residual value

med $=$ Median absolute deviation of residual value and the factor 1.4826 is for consistent estimation in the presence of Gaussian noise and the term $5 /(n-p)$ is recommended as a finite sample correction

Then, the parameters can be estimated by solving the weighted least squares problem:

$\min \sum_{\mathrm{i}} \mathrm{w}\left(\mathrm{r}_{\mathrm{i}}\right) \mathrm{r}_{\mathrm{i}}^{2}$

Equation 13 can be used to modify the quasi-linear transform which adopted by Maged and Mazlan ${ }^{[8]}$, to extract tidal current velocity $\left(\mathrm{V}_{\mathrm{T}}\right)$ from RADARSAT-1 SAR standard mode S2. Therefore, $\mathrm{V}_{\mathrm{T}}$ should be stratified:

$\mathrm{V}_{\mathrm{T}}=\mathrm{H}\left\{\mathrm{V}_{\mathrm{c}} ; \min \sum_{\mathrm{i}} \mathrm{w}\left(\mathrm{r}_{\mathrm{i}}\right) \mathrm{r}_{\mathrm{i}}^{2} ; \mathrm{W}\right\}$

Where:

$\mathrm{H}=$ Represents the linear operator, which is the tidal current-RADARSAT-1 SAR transform

$\mathrm{W}=$ Represents parameters of the tidal currentRADARSAT-1 SAR map, which readily based on the physical conditions of current pattern movements (i.e., velocities and direction) and RADARSAT-1 SAR properties such as $f_{D C}$

Tidal current direction estimation: According to Maged and Mazla ${ }^{[8]}$, the tidal current has two components which are in azimuth and range directions. In this study, the edge of frontal zone is chosen and then divided into sequences of kernel windows with 
frame size of $n \times n$. Due to fact that the frontal zone consists of several adjoining pixels which must have highest signal amplitude than the surrounding pixels. Then, the Doppler spectrum of range compressed RADARSAT-1 SAR data is estimated by performing a Fast Fourier Transform (FFT) in the azimuth direction. Further details of this approach are in Maged and Mazlan ${ }^{[8]}$. The current speed direction $\Theta$ can then be estimated:

$$
\Theta=\tan ^{-1}\left[\frac{\left(\lambda \hat{\mathrm{f}}_{\mathrm{DC}}(\mathrm{a}, \mathrm{r})\right)(2 \sin \theta)^{-1}}{\mathrm{~V}\left(1-\left(1-2 \Delta \mathrm{x} \partial \mathrm{xv}_{\mathrm{s}}\right)^{-0.5}\left(\Delta \hat{\mathrm{f}}_{\mathrm{DC}}(\mathrm{a}, \mathrm{r}) \mathrm{R} \lambda\right)^{-1}\right.}\right]
$$

Where:

$\mathrm{V}=$ Satellite velocity

$\mathrm{R}=$ Slant range

$\Delta \mathrm{x}=$ The displacement vector

$\partial \mathrm{x}=$ The pixel spacing in the azimuth direction

Prior to modeling $f_{D C}$ from the amplitude RADARSAT-1 SAR data, a radiometric correction has been performed. The radiometric correction established a constant correlation between intensity in the SAR data and backscatter in SAR data. The digital number then is converted into the normalized radar cross section $\sigma$ and incident angle to determine the spatial variation of sea surface feature pixels, being a function of $\sigma$ and the incident angle.

\section{RESULTS}

Doppler spectra intensity have acquired with RADARSAT-1 SAR standard (S2) mode that are showed in Fig. 3. In Fig. 3a, the Doppler spectra intensity is tended to varied along the azimuth and range directions in which is inducing ambiguities. Both azimuth and range directions are dominated by the Doppler spectral peak of 0.018 in which is corresponded to the frequency of $150 \mathrm{~Hz}$.

In contrast, Fig. $3 \mathrm{~b}$ shows that the sharp range Doppler spectral intensity peak. The Doppler spectral intensity peak is characterized by narrow peak of 0.025 and frequency band width of $50 \mathrm{~Hz}$.

Figure 4 shows the sea surface current pattern is simulated based on robust technique. It is obvious that the current movement patterns are shown clearly. The current velocity exceeds from offshore towards the coastal within $0.78 \mathrm{~m} \mathrm{sec}^{-1}$. The northeast current flow is a dominated feature along the coastal water of Kuala Terengganu, Malaysia (Fig. 4).

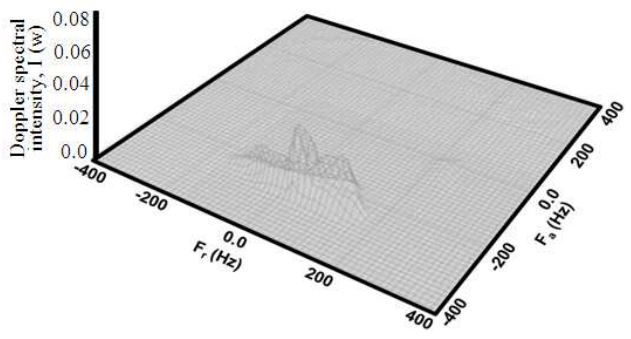

(a)

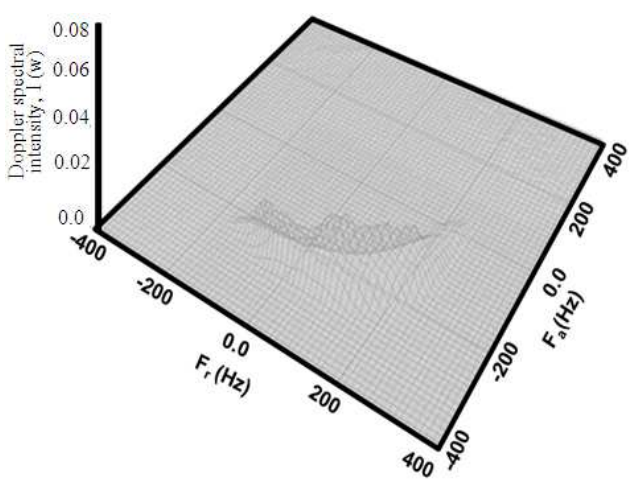

(b)

Fig. 3: Doppler spectra intensity (a): Traditional algorithm and (b): Robust estimators WDAR and MLBF

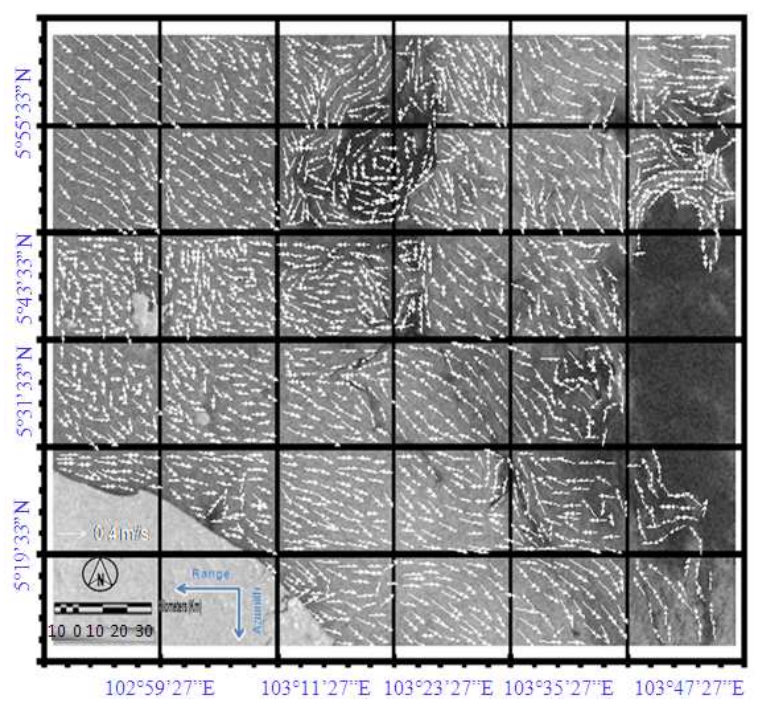

Fig. 4: Sea surface current simulated by using robust estimators for Doppler Centroid

\section{DISCUSSION}

The results show the potential of RADARSAT1SAR standard S2 for retrieving sea surface current pattern which agree satisfactory with previously 
published results ${ }^{[7,10,11,14]}$. In this context, present study confirms the study of Zelina et al. ${ }^{[14]}$, where, March is represented northeast monsoon wind season, in which the current flows from northeast direction and then tends to move parallel to coastline ${ }^{[7]}$. Further, the current flows are deviated from the range direction in which confirms the study of Maged and Mazlan ${ }^{[8]}$.

The Doppler spectra are dominated by ambiguities. In fact, the Doppler frequency estimated from SAR data overcomes from the data are sampled with the Pulse Repetition Frequency (PRF) and an ambiguity about the correct PRF band ${ }^{[13]}$. In addition, the maximum shift along azimuth direction is due to strong nonlinearity occurred between radar signal and surface orbital velocity which can be called as velocity bunching effect $^{[1-6]}$. In contrast, WDAR and MLBF estimators produced a clear and sharp Doppler spectra intensity peak. In fact that robust estimators (WDAR) and MLBF) are estimators which are relatively insensitive to limited variations in the frequency distribution function of the Doppler Centroid frequency $f_{D C}$. Further, both algorithms are capable of retrieving the correct Doppler Centroid ambiguity and to fit a fine polynomial estimate both on uniform and contrasted scenes ${ }^{[13]}$. Clearly, the sharp Doppler spectra peak has existed by using WDAR and MLBF algorithms as compared to one is estimated directly by using traditional Doppler spectra algorithm.

Accuracy of this study is investigated by using the the regression model between the robust statistical analysis between in situ measured ocean current speed and the ocean current speed is simulated based on Doppler centroid ambiguity correction $\mathrm{f}_{\mathrm{DC}}$ (Fig. 5.) The robust statistical model is provided accurately current pattern which is retrieved from RADARSAT-1 SAR standard S2 mode data with standard error of $0.11 \mathrm{~m} \mathrm{sec}^{-1}$. This accuracy is confirmed with $\mathrm{r}^{2}$ of 0.79 . This could be attributed to impact of physical sea surface roughness on backscatter pattern variations in SAR images which allows S2 beam data to detect the sea surface current pattern. In fact, S2 mode data have a lower signal-to-noise due to their $\mathrm{HH}$ polarization with a wavelength of $6.6 \mathrm{~cm}$ and frequency of $5.3 \mathrm{GHz}$. Further, S2 mode data have 3.1 looks and cover an incidence angle of $23.7^{\circ}$ and $31.0^{\circ[2]}$. Thus, $\mathrm{S} 2$ mode data covers a swath width of $100 \mathrm{~km}$ and ground range resolution of $25 \times 28 \mathrm{~m}$. The computational efficiency of sea surface current from S2 mode data, therefore, is improved and fit for real-time processing. In general, SAR ocean current modeling which is based on Doppler centroid analyses through future research perhaps it can provide more accurate and less ambiguous of sea surface current flows in SAR data.

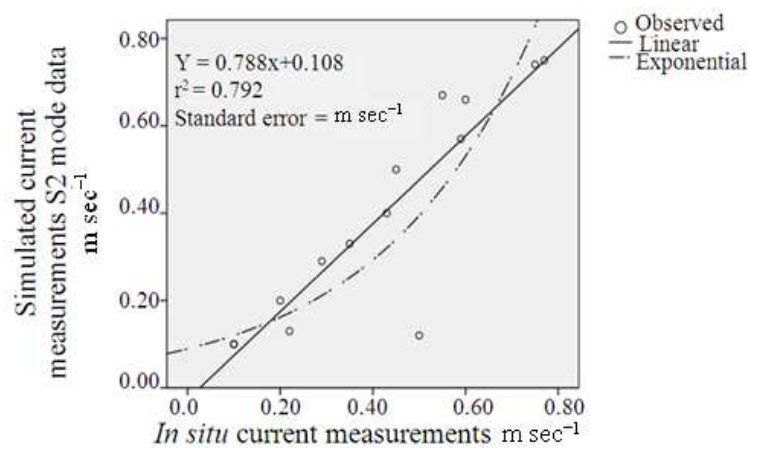

Fig. 5: Regression model of surface current estimated from in situ measurements by AWAC and robust model

\section{CONCLUSION}

It can be concluded that the robust model is examined with RADARSAT-1SAR standard S2 has provided an excellent improvement for extracting ocean surface current from RADARSAT-1 SAR data. This is shown by positive correlation of $\mathrm{r}^{2} 0.79$ and lower standard error of $0.11 \mathrm{~m} \mathrm{~s}^{-1}$. The future work will aim to improve the accuracy of modeling surface current from SAR data by applying an appropriate algorithm and using random variation of spatial AWAC measurements.

\section{ACKNOWLEDGEMENT}

We would like to express our appreciation to University Technology Malaysia Research Management Center (RMC) for a great cooperation. In fact, RMC is providing excellent advice, plans and management for UTM researchers. We also acknowledge the financial e-science grants have received from the Malaysian ministry of science and technology via its intensified research for priority areas programmed.

\section{REFERENCES}

1. Alpers, W.R., D.B. Ross and C.L. Rufenach, 1981. On the detectability of ocean surface waves by real and synthetic aperture radar. J. Geophys. Res., 86: 6481-6498. DOI: 10.1029/JC086iC07p06481

2. Chapron, B., F. Collard and F. Ardhuin, 2005. Direct measurements of ocean surface velocity from space: Interpretation and validation. J. Geophys. Res., 110: C07008-C07025. DOI: 10.1029/2004JC002809 
3. Johannessen, J.A., R.A. Shuchman, G. Digranes, D.R. Lyzenga, C. Wackerman, O.M. Johannessen and P.W. Vachon, 1996. Coastal Ocean fronts and eddies imaged with ERS 1 synthetic aperture radar. J. Geophys. Res. C: Oceans, 101: 6651-6667.

4. Hasselman, K., 1980. A simple algorithm for the direct extraction of the two dimensional surface image spectrum from the return signal of synthetic aperture radar. Int. J. Remote Sens., I: 219-240. DOI: $10.1080 / 01431168008948234$

5. Inglada, J. and R. Garello, 1999. Depth estimation and 3D topography reconstruction from SAR images showing underwater bottom topography signatures. Proceedings of the IEEE International Geoscience and Remote Sensing Symposium, June 28-July 2, IEEE Xplore Press, Hamburg, Germany, pp: 956-958. DOI: 10.1109/IGARSS.1999.774497

6. Inglada, J. and R. Garello, 2002. On rewriting the imaging mechanism of underwater bottom topography by synthetic aperture radar as a Volterra series expansion. IEEE J. Ocean. Eng., 27: 665-674. DOI: 10.1109/JOE.2002.1040949.

7. Maged, M., M. Hashim and A. Cracknell, 2009. 3D reconstruction of coastal bathymetry from AIRSAR/POLSAR data. Chinese J. Oceanol. Limnol., 27: 117-123. DOI: 10.1007/s00343-0090117-9

8. Maged, M. and H. Mazlan, 2006. Threedimensional reconstruction of bathymetry using CBand TOPSAR. Data PhotogrammetriFernerkundung Geoinform., 6: 469-480.

9. Rufenach, C.L., R.A. Shuchman and D.R. Lyzenga, 1983. Interpretation of synthetic aperture radar measurements of ocean currents. J. Geophys. Res., 88: 1867-1876. DOI: 10.1029/JC088iC03p01867
10. Romeiser, R. and D.R. Thompson, 2000. Numerical study on the along-track interferometric radar imaging mechanism of oceanic surface currents. IEEE Trans. Geosci. Remote Sens., 38: 446-458.

http://cat.inist.fr/?aModele $=$ afficheN\&cpsidt $=1252$ 582

11. Romeiser, R., H. Breit, M. Eineder, H. Runge, P. Flament, K. de Jong and J. Vogelzang, 2003. On the suitability of terrasar-x split antenna mode for current measurements by along-track interferometry. Proceedings of the IEEE International Geoscience and Remote Sensing Symposium, July 21-25, IEEE Xplore Press, USA., pp: 1320-1322. DOI: 10.1109/IGARSS.2003.1294095

12. Shemer, L., M. Marom and D. Markman, 1993. Estimates of currents in the nearshore ocean region using interferometric synthetic aperture radar. J. Geophys. Res., 98: 7001-7010.

13. Stefano, D. and A.M. Guarnieri, 2003. Robust doppler centroid estimate for ERS and ENVISAT. Proceedings of the IEEE International Geoscience and Remote Sensing Symposium, July 21-25, IEEE Xplore Press, USA., pp: 4062-4064. DOI: 10.1109/IGARSS.2003.1295362

14. Zelina, Z.I., A. Arshad, S.C. Lee, S. Japar, A.T. Law, R.A. Nik Mustapha and M.M. Maged, 2000. East Coast of Peninsular Malaysia. In: Sea at the Millennium: An Environmental Evaluation, Sheppard, C. (Ed.), Vol. II, Oxford, ISBN: 13: 9780-08-043207-6, pp: 345-359. 